\title{
LA PASIÓN POR EL VACÍO: \\ ANÁLISIS SEMIÓTICO DE UN POEMA DE JOSÉ WATANABE
}

\section{Marcos Mondoñedo*}

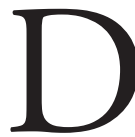

eseamos comenzar con una alusión externa a la semiótica o, por lo menos, mucho más antigua que ella: se trata de la lógica modal. Y lo más elemental de esta lógica es el reconocimiento de sus cuatro términos analíticos: Necesario, Imposible, Contingente y Posible. Se trata de cuatro situaciones de existencia, de cuatro modalidades por las que los enunciados pueden ser considerados: lo que deónticamente debe ser o resulta obligatorio es lo necesario; lo que en cuanto al deber resulta prohibido es modalmente lo imposible; aquello considerado como indiferente es la modalidad de lo contingente, y lo que es leído como lícito resulta ser lo posible. ${ }^{1}$

Dentro del ámbito de la semiótica también podemos encontrar una cierta lógica modal; se trata, como es sabido de los predicados modales del querer, poder, saber, creer, deber y el hacer. Estas modalidades se distribuyen en virtualizantes, actualizantes, potencializantes y realizantes. Una aplicación de dichas modalidades que podemos destacar a modo de ejemplo es la de la

*Es docente de la Facultad de Letras y Ciencias Humanas de la Universidad Nacional Mayor de San Marcos.

1 Hacemos esta correlación con la lógica deóntica para definir en un intento metateórico los términos concernidos en la lógica modal; no desarrollaré, sin embargo, esta correlación, salvo como una apoyatura descriptiva. 
«praxis enunciativa». Dentro de ella podemos observar estos mismos cuatro modos de presencia que a su vez se corresponden con cuatro modalidades de los enunciados entendidos como parte del discurso; se trata de los modos virtualizado, actualizado, potencializado y realizado.

Estos modos, no obstante, al ser correlacionados con la lógica modal no resultan del todo compatibles. Dicho en otras palabras, cuando intentamos establecer una suerte de correspondencia biunívoca entre los términos de un campo con los del otro, nos encontramos con que lo imposible modal no se traduce, por lo menos no de manera nítida con la modalización discursiva:

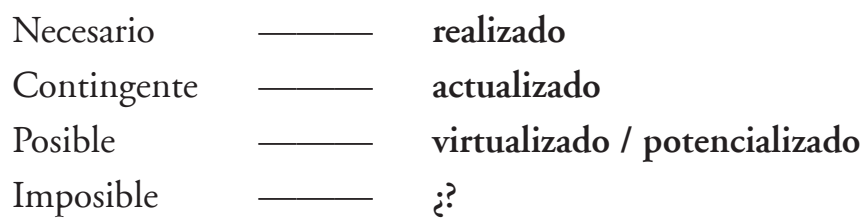

Decimos que lo necesario se corresponde con lo realizado puesto que en ambos casos se trata de una condición obligatoria. Al respecto Leibniz sostiene que un predicado es necesario cuando está implícito en el sujeto (se trataría de un juicio analítico a priori, en términos kantianos). Decir, por ejemplo, que un dictador restringe las libertades es pronunciar un enunciado necesario en la medida en que un dictador se describe como aquel que restringe las libertades; no puede haber un dictador sin tal restricción. En el caso de la semiótica, el modo realizado alude al momento en el que el plano de la expresión se configura en correlación con el plano del contenido, se trata de una articulación particular que trae como resultado una concreción discursiva. Como sostiene Fontanille, en el modo realizado, el enunciado se encuentra con la realidad articulada, «realidad material de la expresión, realidad del mundo natural y del mundo sensible en el plano del contenido" (Fontanille 2001: 239). Para que exista la semiosis debe ocurrir esta determinada articulación; no hay significación sin ella. Como vemos, en ambos casos resulta irrenunciable la condición que los constituye — de 
ahí su carácter de necesidad: un dictador lo es necesariamente si restringe las libertades, un discurso lo es en tanto concreto si produce la semiosis o significación-.

Por su parte, correlacionamos de la lógica modal la contingencia con el modo actualizado debido a que este describe el pasaje a la realización discursiva de aquello que todavía no es un discurso concreto y puede serlo. Volviendo a nuestra referencia filosófica anterior, Leibniz sostiene que un enunciado contingente es aquel cuyo contrario no produce una contradicción: si César cruza el Rubicón o gana la jornada de Farsalia, estos son hechos cuyos contrarios no producen una contradicción respecto de César, el no deja de ser César si gana o no gana dicha jornada, en cambio deja de ser un dictador en caso de que deje de restringir las libertades. En el caso de la praxis enunciativa, si bien en el tránsito de lo virtual hacia lo realizado se describen procedimientos discursivos, un discurso solo adquiere el rango de coherencia retrospectivamente: podemos producir una hipótesis generativa que dé cuenta del proceso de actualización de dicho estado final o producto discursivo una vez que el discurso adquiere su modalidad realizada. Pero, por un lado, dicho recorrido es en sí mismo hipotético y, por el otro, el proceso de actualización no establece reglas fijas y necesarias que conlleven la realización de los discursos. Los discursos no se realizan en serie; aun cuando podemos reconocer una lógica isotópica en un conjunto de ellos y atribuirle lo que denominamos rasgos de un género, la realidad del discurso es su diversidad, su diferenciación individual a pesar de compartir un mismo campo isotópico. Y esta diferencialidad es lo que la actualización consagra. Es por ello, porque no es posible determinar reglas necesarias para la realización discursiva, que la actualización deviene contingente: un discurso en concreto pudo actualizarse de un modo distinto al modo en que actualizó, ello no genera ninguna contradicción respecto de lo discursivo; de ahí, repetimos, su carácter contingente.

Finalmente, lo posible en lógica modal se convierte en dos modalidades enunciativas, la potencializada y la virtualizada. Esto es así, en la medida en que ambas describen lo que no tiene una existencia ni realizada ni 
actualizada, sino mas bien refieren lo que resulta o subyace como estructura sistemática a toda actualización-realización o lo que resulta disponible siendo que se conserva en la tradición para ser usado en cualquier otra actualización discursiva. Tanto lo virtual como lo potencial son el no discurso; son la instancia de la que, sin embargo resulta posible devenir en discurso: se trata de dos modos de bagaje o competencia previa de toda realización, el sistemático abstracto o aquel del tesoro de realizaciones pasadas que se conservan en la tradición y la memoria.

Luego de esta breve correlación, resulta evidente que lo imposible, que en términos deónticos es lo prohibido, no resulta pertinente o no halla su correlato en las modalidades enunciativas. Es verdad que lo prohibido se encuentra en la reflexión que en torno al cuadrado semiótico se realiza sobre los recorridos fundamentales que dicho cuadrado permite describir, pero se alude a lo prohibido para sostener precisamente que ese es un recorrido impertinente, no discursivo.

Por el contrario nosotros creemos que lo imposible puede y debe incluirse en la reflexión sobre la praxis enunciativa y que el olvido de esa dimensión atenúa o descompleta las posibilidades de la significación.

Es probable que, dentro del campo de la semiótica, el descrédito por las estructuras abstractas como el cuadrado semiótico, en relación a su dificultad respecto de relacionarlo con un discurso realizado, haya contribuido a este olvido e incluso rechazo de lo imposible como modalidad pertinente. En algún momento se pensó, quizá erróneamente, que el hecho según el cual, todo análisis semiótico greimasiano terminara en el cuadrado de las oposiciones contrarias y contradictorias, cuyos ejes eran siempre los de la vida y la muerte, y los de la naturaleza y la cultura era poco rentable cognoscitivamente, ¿qué sentido tiene llegar a ese punto de la intuición inicial?, ¿qué discurso en Occidente no alude, finalmente, a estas dimensiones en lo más fundamental? Desde este punto de vista, la reivindicación de la praxis enunciativa como un proceso o como un acto habría tratado de liberarse de esa contundente crítica. Poner énfasis en el proceso de actualización y no ya 
en la estructura virtual, como quería Hjelmslev, resulta, entonces, un giro saludable y productivo cognoscitivamente.

No obstante, este nuevo énfasis del proceso de actualización y de realización del discurso ha traído como consecuencia el olvido de la negatividad radical propia de la constitución de lo sistemático virtual y, como consecuencia, el rechazo de la factibilidad de lo imposible en el discurso. Tomando esto como punto de partida $-\mathrm{y}$ a riesgo de parecer un simple malabarista de las palabras- preguntaré: ‘acaso no resulta posible que lo imposible devenga en el discurso realizado? ¿Acaso no es posible que lo imposible se presente, sea presencia, se «presentifique», si cabe el término? Nuestra hipótesis es que lo imposible deviene, se presenta, que se actualiza e incluso se realiza. Se me dirá — se me ha dicho—, en realidad: «lo imposible es el no discurso, lo imposible es lo que está por fuera de toda significación» y es aquí que me parece importante destacar algo: si realmente lo imposible es aquello externo al discurso, eso quiere decir que existe algo más allá, una especie de cosa en sí kantiana, un real más allá de toda posibilidad cognoscitiva que de este modo resulta imposible. Pues bien, si hay algo incognoscible que no pertenece a la significación, propongo — por oposición a esta perspectiva a todas luces kantiana - la posibilidad de realizar un giro hegeliano e incluir ese imposible en la significación y, de este modo, plantear que todo lo imposible es significativo y todo lo significativo es imposible.

Esto último, que todo lo significativo sea imposible requiere de un desarrollo que hoy no podemos efectuar. En todo caso dejo apuntado que lo imposible y lo prohibido, se configuran por un no radical, por la negatividad que engendra el sistema; se trata nada menos que de la diferencialidad que permitió a Saussure instaurar el carácter científico de la Lingüística y lo habilitó para decir que la lengua es el espacio de la pura diferencia, la cual no posee entidades sustanciales. De este modo, todo lo que cae bajo el dominio de la significación se sostiene en y se produce a partir del no radical de lo imposible.

Lo otro, que todo lo imposible sea significativo, alude al hecho del devenir, de la aparición de lo imposible en el discurso. Podría sostenerse 
entonces que si lo imposible es significativo deja de ser imposible y deviene en actualizado o en realizado. En esta ocasión queremos plantear que la modalidad de lo imposible sin dejar de serlo, conservando su estatuto, interviene en la significación de una manera muy especial. Para probar este fenómeno, queremos realizar el análisis semiótico de un poema de Watanabe que trata sobre la pasión, la del hijo de la Virgen María. Se trata de «La crucifixión» de su poemario Habitó entre nosotros (2002).

\section{LA CRUCIFIXIÓN}

Elevado en la cruz, hijo mío, te haces cada vez más vertical: tu cabeza injuriada por espinas

ya toca las más altas nubes.

No te puedo alcanzar, no puedo

cerrar tu herida con mi mano,

$$
\text { y la sustancia dorada }
$$

que te dio el Padre

te sigue abandonando por la lanzada

$\mathrm{Al}$ aire han vuelto los olores

de tu nacimiento. Ay niño mío,

$$
\text { crucificado desde siempre }
$$

tu sangre cae

$$
\text { y quema la tierra }
$$

y quema los siglos. El tiempo de los pobres y el tiempo de los reyes,

$$
\text { con su cada hora, tendidos, }
$$

están ardiendo a tus pies.

Mañana todo será nuevo, menos este dolor infinito. Y no hay consuelo, 
solo una pregunta que grito

y acaso Tú reprochas:

¿Era necesario

que la carne de mi carne

sea entregada como alianza

entre la ingrata tierra y el cielo?

(Watanabe 2002: 55)

Desde la perspectiva de la semiótica tensiva, una primera descripción es aquella de la ubicación de las presencias puestas en juego en el discurso. En este caso se trata de una madre que contempla el padecimiento y sacrificio de su hijo. La primera presencia, la madre, se ve afectada internamente por los estados de cosas del mundo exterior que se imprimen sobre su piel y producen una conmoción interna, que puede ser descrita como una impotencia y un dolor muy grandes. Se trata de una primera articulación semisimbólica, entre un plano llamado exteroceptivo, aquel del mundo exterior o plano de la expresión y otro interoceptivo el cual se corresponde con los estados de ánimo del mundo interior o plano del contenido. De este modo podemos proponer este primer esquema elemental:

"cada vez más vertical»

«cabeza injuriada por espinas»

«tu herida»

«los olores de tu nacimiento»

[Impotencia]

[Sufrimiento] 
Desde este primer análisis podemos observar una continuidad entre el hijo y la madre como el anverso y el reverso de una misma membrana sensible: todo lo que le sucede al hijo es sentido como duros acicates sobre la propia piel de la madre, esto sacude fuertemente la carne interior materna. Pero este es casi un saber de sentido común: existen entre nosotros frases hechas y melodramáticas las cuales afirman que «una madre se ha hecho para sufrir» o "nadie sabe todo lo que tiene que sufrir una madre por sus hijos» $\mathrm{o}$ «todo lo que el hijo padece lo siente la madre» y así una infinidad de enunciados que tiene como base esta relación entre el derecho y el revés de una piel sensible. No obstante, debemos admitir que este fenómeno puede tener como historia prístina, como paradigma la relación entre María y su hijo aquí aludidos.

Por otro lado, en la descripción realizada podemos observar momentos de embrague que intentan recuperar la posición inicial, la de la primera presencia, lo vemos en el pasaje en el que la madre se lamenta y dice «Ay niño mío, / crucificado desde siempre», es un intento de retorno a la primera toma de posición ante el mundo.

En un segundo momento podemos observar un desembrague muy marcado debido al contraste con respecto al anterior procedimiento de embrague - aquel de la manifestación de dolor aludida, la conmoción interna de la madre- En este siguiente pasaje se nos presenta al hijo cuya sangre cae y quema. Se produce, entonces, una transfiguración de un líquido elemental en fuego. Cabe sospechar que esta modificación metafórica es posible gracias al color rojo que compartirían la sangre y el fuego. La sangre y el fuego son dos contenidos en pugna a partir de una misma expresión, el color rojo; esta articulación semisimbólica permite, pues, sostener que la sangre queme.

Lo impresionante es que esta transfiguración de la sangre en fuego prepara e inmediatamente posibilita la desconfiguración de la verosimilitud hasta aquí respetada y la ampliación de su campo de pertinencia. Se rompe la isotopía de la crucifixión de un cuerpo y se produce una explosión en donde, sin embargo, confluyen, como cuatro puntos cardinales que se reúnen a 
los pies del hijo, los reyes y los pobres, el espacio y el tiempo; todos son quemados y purificados en ese incendio:

tu sangre cae

y quema la tierra

y quema los siglos. El tiempo de los pobres

y el tiempo de los reyes,

con su cada hora, tendidos,

están ardiendo a tus pies.

En este momento se produce la trascendencia de la relación elemental entre la carne de la madre y la piel del hijo. Es el instante de la apertura al mundo más allá de esta relación exclusivamente semisimbólica y sensible. Los tiempos se incorporan a la tierra y los hombres de contrarias condiciones se amalgaman, todo lo cual nos podría dar a entender que este pasaje configura una anisotopía previa a la sustitución de este amasijo indiscernible por el fuego y la sumisión.

En el último pasaje, retorna la figura de la madre; se produce otro repliegue o embrague luego del anterior desembrague.

Mañana todo será nuevo, menos este dolor infinito. Y no hay consuelo, solo una pregunta que grito

y acaso Tú reprochas:

¿Era necesario

que la carne de mi carne

sea entregada como alianza

entre la ingrata tierra y el cielo? 
En este momento, sin embargo ya no se produce un semisimbolismo doliente como el anterior; en este caso, se habla de una alianza. El hijo ha pasado al lado del Padre. Ha vencido el Padre y lo que queda es el reclamo de la Madre: «¿Era necesario...?». Todos sabemos la respuesta: sí, lo es; no lo era. La madre que sufre es una madre como muchas que pudieron haber sufrido por sus hijos, no vemos en esta madre nada diferente o, más precisamente, ella es un ejemplar representativo o parangón de todas las madres que sufren por los descendientes. Una respuesta más puntual a la pregunta formulada sería que no era necesario sino posible y, solo por contingencia, devino en necesario.

A todo esto se me preguntará, ¿y lo imposible?, ¿no es evidente en este instante que no tienen ninguna pertinencia? A lo cual podemos responder, lo imposible, lo que «no cesa de no inscribirse» en este poema, lo que en todo momento se evade y se contornea es el nombre del hijo de Dios. Esto se confirma con el propio nombre del poemario, Habitó entre nosotros, que elude el nombre o los nombres del hijo de María, y con todos los poemas incluidos en esta pasión, en ninguno de los cuales se menciona alguno de los aludidos nombres. Ahora mismo estamos intentándolo nosotros, y lo hacemos para ubicar de un modo contrariado una cierta sensación de imposible, de prohibido respecto de aquel o aquellos nombres no dichos, en nuestro desarrollo argumental.

Es como si estuviera prohibido y, evidentemente (con una evidencia negativa), no cesa de no estar escrito en el poemario. Verificamos lo imposible a partir de su carácter deóntico de permanecer prohibido en el texto de Watanabe.

Pero esto es una mera constatación, y debería verse confirmada con alguna otra circunstancia en el poema. ¿Existe algo como un NO que sea radical, como una ausencia o como un vacío en torno del cual giran los otros componentes del discurso? Veamos nuevamente los primeros versos:

Elevado en la cruz, hijo mío, te haces cada vez más vertical: tu cabeza 


$$
\begin{aligned}
& \text { injuriada por espinas } \\
& \qquad \text { ya toca las más altas nubes [...]. }
\end{aligned}
$$

En este grupo de versos vemos la cabeza que se proyecta hacia las nubes. Podemos destacar, entonces una relación entre la cabeza y las nubes o incluso el cielo. Si pretendemos que esta correlación sea analógica y genere una isotopía, debe completarse con otro par articulado. Para ello, echemos otra mirada a los siguientes versos:

\section{tu sangre cae}

y quema la tierra

y quema los siglos. El tiempo de los pobres

y el tiempo de los reyes [...]

A partir de lo visto, podemos correlacionar la sangre con la tierra, con el tiempo humano, con los hechos propios del reino de este mundo. Ordenando todo, observamos que la cabeza tiende y se proyecta hacia el cielo, mientras que la sangre se dirige a la tierra:

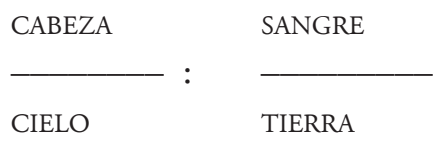

Esta homología se ve confirmada con los versos finales en los cuales se declara que hubo un pacto o «alianza / entre la ingrata tierra y el cielo». Pero viéndolo así, ‘acaso no hay un término medio, no dicho e imposible de decir?; con mayor precisión debiéramos sostener que más que un término ¿no sería antes bien un no-término, un vacío, un agujero el que en este momento nos interpela? Si la cabeza tiende hacia las nubes del cielo y la sangre se precipita y quema la tierra, ¿no estamos precisamente ante un desgarramiento, ante un medio que se forma, un vacío que genera y es 


\section{MARCOS MONDOÑEDO}

generado por esta tensión antagónica, por estos tirones de la madre hacia la tierra y del padre hacia el cielo?

El hijo de María entonces se deshumaniza en el justo momento de su intensa y humana o inhumana pasión, se hace vínculo o posibilidad de vínculo entre lo significantes terrestres y los divinos. Pero solo con la condición de devenir en un contundente NO, un no-hijo, un no-dios, una nada, un imposible de ser inscrito que no cesa de no estar para que todo lo demás confluya y armonice.

En conclusión, la constante evitación de aquel nombre que genera una sensación de prohibido en el poema se confirma con el vacío en el que deviene el hijo de María, un vacío o desgarrón o resquebrajamiento que permite o hace posible el lazo, lo garantiza y de este modo concede, además, la significación particular de «La crucifixión». De este modo, en esta ficción de la cruz, bajo la forma de lo negado y de lo vaciado, lo imposible deviene imprescindible para la semiosis. Debiéramos hacerle frente y en ningún caso evadir esta dimensión ya de por sí evasiva. Pese a su dificultad, ella es de todos modos eficaz o por lo menos concurrente en el proceso de la significación. El que no implique lo sensible o que sea el revés de lo sensible no debiera hacernos retroceder. 


\section{BIBLIOGRAFÍA}

ARISTÓTELES

1996 Lecciones sobre la naturaleza (Física). Madrid: Consejo Superior de Investigaciones Científicas.

FonTANILLE, Jacques

2001 Semiótica del discurso. Lima: Universidad de Lima y FCE.

LACAN, Jacques

1975 Libro 20. Aun. 1972-1973. Texto establecido por Jacques-Alain Miller. Buenos Aires: Paidós.

LeIBNIZ, Gottfried Wilhelm

1955 Discurso de metafísica. Traducción de Alfonso Castaño Piñán. Buenos Aires: Aguiar. (tít. orig. Discours de métaphysique y fue escrito en el invierno de 1685-86 para el landgave Ernst von Hesse-Rheinfels).

Trilles Montero, J. Óscar

2001 Apuntes de lógica modal. Lima: Fondo Editorial de la Pontificia Universidad Católica del Perú.

WATANABE, José

2002 Habitó entre nosotros. Lima: Fondo Editorial de la Pontificia Universidad Católica del Perú. 